\title{
A meta-analysis of late outcomes of mitral valve repair in patients with rheumatic heart disease
}

\author{
Jin-Tao Fu ${ }^{1}$, Mohammad Sharif Popal ${ }^{1}$, Hai-Bo Zhang ${ }^{1}$, Wei Han ${ }^{1}$, Qiu-Ming Hu ${ }^{1}$, Xu Meng ${ }^{1}$, Chun-Ye Ma ${ }^{2}$ \\ ${ }^{1}$ Department of Cardiac Surgery, Beijing Anzhen Hospital, Capital Medical University, Beijing 100029, China; ${ }^{2}$ Department of Cardiac Surgery, \\ Baiqiuen No. 1 Hospital, Jilin University, Changchun 130000, China \\ Contributions: (I) Conception and design: X Meng, CY Ma; (II) Administrative support: X Meng; (III) Provision of study materials or patients: JT Fu, \\ MS Popal; (IV) Collection and assembly of data: JT Fu, MS Popal, W Han; (V) Data analysis and interpretation: JT Fu, HB Zhang, QM Hu; (VI) \\ Manuscript writing: All authors; (VII) Final approval of manuscript: All authors. \\ Correspondence to: Xu Meng. Department of Cardiac Surgery, Beijing Anzhen Hospital, No. 2 Anzhen Road, Chaoyang District, Beijing 100029, \\ China. Email: mxu@263.net; Chun-Ye Ma. Department of Cardiac Surgery, Baiqiuen No. 1 Hospital, Jilin University, Changchun 130000, China. \\ Email: victory1260601@126.com.
}

Background: Rheumatic heart disease (RHD) is a predominant health concern in developing countries. The aim of this meta-analysis was to evaluate the outcomes of mitral valve (MV) repair in patients with RHD, and identify predictors that may postoperatively affect treatment outcome.

Methods: A meta-analysis of eligible studies assessing patients undergoing MV repair with RHD and reporting the outcomes of MV repair, including 30-day mortality and long-term follow-up survival, MV reoperation rate and postoperative adverse events. Relevant English articles were searched up to 1 March, 2017 in Web of Science, PubMed, Google Scholar, Cochrane Library, EmBase, Elsevier, and Science Direct. Selected studies should meet all inclusion criteria, and underwent data extraction.

Results: A total of ten studies with 2,770 patients met all inclusion criteria, and were selected for assessment. Pooled analysis showed that 30-day mortality in patients with rheumatic MV disease after MV repair surgery was $1.9 \%, 95 \%$ confidence interval (CI) (0.8-2.9\%); long-term survival was $97.3 \%, 95 \%$ CI (95.9-98.6\%), and a freedom from reoperation rate of 93.6\%, 95\% CI (91.4-95.9\%) was obtained; freedom from adverse events was $97.5 \%, 95 \%$ CI (95.2-99.8\%).

Conclusions: The outcome of rheumatic MV repair is outstanding in terms of low early mortality, high long-term survival and freedom from valve-related complications, which may be very common in patients after rheumatic MV replacement; meanwhile, MV reoperation rate after initial surgery is acceptable. Surgeons may try to repair MV in RHD when it is feasible

Keywords: Rheumatic heart disease (RHD); mitral valve (MV) repair; outcomes; meta-analysis

Submitted Aug 30, 2017. Accepted for publication Oct 13, 2017.

doi: $10.21037 /$ jtd.2017.10.97

View this article at: http://dx.doi.org/10.21037/jtd.2017.10.97

\section{Introduction}

Rheumatic heart disease (RHD) remains one of the major causes of mitral valve (MV) disease among children and adults worldwide, especially in developing countries (1). RHD is the most severe long-term sequela of rheumatic fever (2); indeed, approximately $30 \%$ of patients with rheumatic fever may develop RHD. Patients with severe
RHD who do not undergo surgical treatment will eventually die. Mitral stenosis (MS), mitral regurgitation (MR) and mixed lesions result from rheumatic MV disease, which eventually causes heart failure. Both MV repair and MV replacement are beneficial to patients; even in some developing countries, MV replacement is still considered the preferred surgical method for RHD patients because of low rate of reoperation. In China specifically, the 
feasibility of MV repair for RHD patients is extremely low. However, other studies $(3,4)$ believed that MV replacement may not be the most optimal surgical treatment for such patients, demonstrating the advantages of MV repair over replacement in terms of low rate of early mortality, better late survival, preservation of left ventricular function, and reduced anticoagulant-related complications. Here, we systematically reviewed published literature and performed a meta-analysis which assessed the outcomes of MV repair in patients with RHD, exploring predictive factors that may postoperatively affect treatment outcome.

\section{Methods}

\section{Literature search}

Web of Science, PubMed, Cochrane Library, Google Scholar, EmBase, Elsevier, and ScienceDirect were independently searched by two authors (JT Fu, MS Popal) for potentially relevant studies which analyzed the outcomes of MV repair for rheumatic MV disease, up to 1 March, 2017. The following key terms were used either alone or in combination: "rheumatic heart disease", "RHD", "mitral valve repair", "MVP", "mitral valve reconstruction", and "mitral valve surgery". Some references in relevant studies were hand searched for additional articles which could not be identified by the advanced search.

\section{Selection criteria}

The inclusion criteria were: (I) directly analysis of $\mathrm{MV}$ repair outcomes for RHD; (II) articles reported at least one of postoperative outcomes such as early mortality (defined as death occurring within 30 days after MV surgery), longterm survival/mortality (defined as death occurring more than 30 days after surgery and during the follow-up period), and any major anticoagulant-related complications which include hemorrhage and thromboembolism, hemolysis, and reoperation rate of MV; (III) all included patients with RHD; (IV) MV repair as initial procedure. Exclusion criteria were: (I) articles not in English; (II) degenerative, myxomatous and other non-rheumatic heart disease; (III) studies with $<45$ patients who underwent MV repair to minimize bias; (IV) case reports, review, descriptive studies, and abstracts with no full texts retrieved in the above databases. When multiple articles were retrieved from the same author, colleagues or institution, only the largest study was selected.

\section{Data extraction and statistical analysis}

Two authors (JT Fu, MS Popal) extracted data from the selected articles on standardized forms; any disagreements were resolved by seeking the opinion of the third author ( $\mathrm{HB}$ Zhang) or by consensus. we used an 11-item checklist which was recommended by Agency for Healthcare Research and Quality (AHRQ) assessed the quality of studies. The metaanalysis complied with the meta-analysis of observational studies in epidemiology (MOOSE) recommendations (5). Sample size, year of publication, first author, outcome events, etiology of valve disease, and baseline demographics in all eligible studies were extracted. Analyses were conducted based on the intention to treat principle. We could not account for possible censored observations that might have resulted from incomplete follow-up in individual studies, due to the lack of relevant information. A random effects model was employed to assess summary estimates and 95\% confidence intervals (CIs) for each outcome event. A sensitivity analysis was performed, also assessing the influence of excluding individual studies on the summary effect estimate. All analyses were carried out with Stata 12.0.

\section{Results}

A total of 24,176 potentially relevant publications were identified from all databases and our selection process was shown in Figure 1. Finally, ten studies evaluating 2,770 patients met all eligibility criteria, and were included in the meta-analysis. The characteristics of the selected studies are listed in Table 1. The period of publication was 2005-2017. All 2,770 patients with rheumatic MV disease underwent MV repair, and baseline demographics, pathologic features, and follow-up years are summarized in Table 2. Outcomes at follow-up after MV repair surgery are provided in Table 3.

\section{Thirty-day mortality}

All ten studies reported 30-day mortality. Three of them reported 30-day mortality was $0 \%$; the values ranged from $0.5 \%$ to $6.0 \%$ in the remaining studies. Pooled analysis showed 30-day mortality after MV repair surgery in patients with rheumatic MV disease is $1.9 \%$, (95\% CI, $0.8-2.9 \%)$ (Figure 2).

\section{Long-term survival}

Long-term survival data were available for all ten studies. 


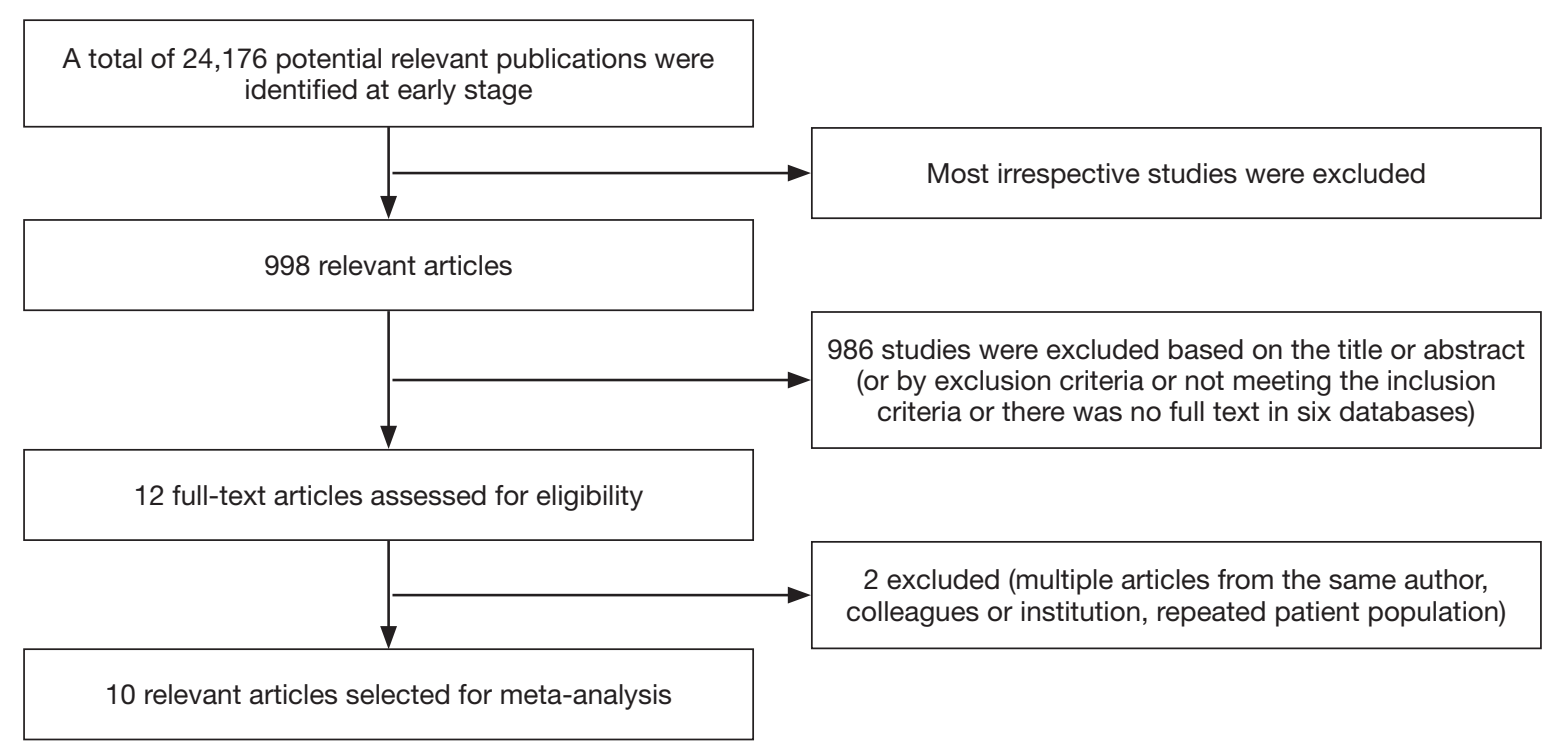

Figure 1 Flow chart of the selection process.

Table 1 Study characteristics

\begin{tabular}{lcccc}
\hline Study name & Country & Study period & Total patients & \multicolumn{1}{c}{ Design } \\
\hline Fedakar et al. (6) & Turkey & $1998-2008$ & 173 & Observational \\
Yankah et al. (7) & Germany & $1986-2009$ & 50 & Observational \\
Severino et al. (8) & Brazil & $1994-2005$ & 104 & Observational \\
Kim et al. (9) & Korea & $1997-2010$ & 193 & Observational \\
Yakub et al. (10) & Malaysia & $1997-2010$ & 627 & Observational \\
Waikittipong et al. (11) & Thailand & $2003-2014$ & 97 & Observational \\
Kumar et al. (12) & India & $1988-2003$ & 898 & Observational \\
Kalangos et al. (13) & Switzerland & $1994-2006$ & 220 & Observational \\
El Oumeiri et al. (14) & Belgium & $1996-2007$ & 78 & Observational \\
Pomerantzeff et al. (15) & Brazil & $1985-2005$ & 330 & Observational \\
\hline
\end{tabular}

Pooled analysis of the selected studies showed that longterm survival after MV repair surgery in patients with rheumatic MV disease was $97.3 \%$ (95\% CI, 95.9-98.6\%) (Figure 3).

\section{Freedom from reoperation}

Freedom from reoperation rates were reported in all ten studies. However, one study did not provide the detailed number of patients that accepted additional mitral surgery; therefore, the data could not be used to calculate overall freedom from reoperation rate. Pooled analysis of the nine remaining studies showed freedom from reoperation rate after $\mathrm{MV}$ repair surgery in patients with rheumatic $\mathrm{MV}$ disease was 93.6\% (95\% CI, 91.4-95.9\%) (Figure 4).

\section{Freedom from adverse events}

Of the ten included articles, seven provided the detailed number of adverse events. Thus, data were extracted from the seven articles to assess freedom from valve-related complications. Pooled analysis showed that freedom from 
Table 2 Baseline patient demographic and pathological features, and follow-up period

\begin{tabular}{|c|c|c|c|c|c|}
\hline Study name & Mean age (years) & Previous MR & Previous MS/mixed & Males (number) & Mean follow-up years \\
\hline Yankah et al. (7) & 45.6 & 37 & 13 & 18 & 6.02 \\
\hline Severino et al. (8) & 32.7 & 37 & 67 & 22 & $5.3 \pm 3.3$ \\
\hline Kim et al. (9) & 39.4 & 146 & 47 & 39 & $6.4 \pm 3.8$ \\
\hline Waikittipong et al. (11) & 24.0 & 79 & 18 & 23 & $4.9 \pm 2.7$ \\
\hline Kumar et al. (12) & 22.4 & 412 & 486 & 390 & $5.2 \pm 2.7$ \\
\hline Kalangos et al. (13) & 11.8 & 198 & 22 & 78 & $6.4 \pm 3.2$ \\
\hline El Oumeiri et al. (14) & 56.4 & 38 & 40 & 26 & $5 \pm 3$ \\
\hline
\end{tabular}

MR, mitral stenosis; MS, mitral regurgitation.

Table 3 Outcomes at follow-up after MV repair surgery

\begin{tabular}{|c|c|c|c|c|}
\hline Study name & $\begin{array}{l}\text { 30-day } \\
\text { mortality (\%) }\end{array}$ & $\begin{array}{l}\text { Long-term } \\
\text { survival (\%) }\end{array}$ & $\begin{array}{l}\text { Freedom from } \\
\text { reoperation (\%) }\end{array}$ & $\begin{array}{l}\text { Freedom from } \\
\text { valve-related event (\%) }\end{array}$ \\
\hline Fedakar et al. (6) & 2.3 & $\begin{array}{l}93.3 \text { ( } 5 \text { years); } \\
93.3 \text { (10 years) }\end{array}$ & 89 & Unknown \\
\hline Yankah et al. (7) & 6 & $\begin{array}{l}84.7 \text { ( } 5 \text { years); } \\
66.9 \text { (10 years); } \\
50.2 \text { (15 years) }\end{array}$ & $\begin{array}{l}77.3 \text { ( } 5 \text { years); } \\
53.4 \text { (10 years) }\end{array}$ & Unknown \\
\hline Kim et al. (9) & 0.5 & $\begin{array}{l}96.7 \text { (5 years); } \\
92.2 \text { (10years) }\end{array}$ & $\begin{array}{l}97.5 \text { ( } 5 \text { years); } \\
96.7 \text { (10 years) }\end{array}$ & $\begin{array}{l}90.3 \text { ( } 5 \text { years); } \\
85.5 \text { (10 years) }\end{array}$ \\
\hline Yakub et al. (10) & 2.4 & $\begin{array}{l}99.7 \text { ( } 5 \text { years); } \\
98.1 \text { (10 years) }\end{array}$ & $\begin{array}{l}91.8 \text { ( } 5 \text { years); } \\
87.3 \text { (10 years) }\end{array}$ & $\begin{array}{l}85.6 \text { ( } 5 \text { years); } \\
72.8 \text { (10 years) }\end{array}$ \\
\hline Kumar et al. (12) & 3.6 & $\begin{array}{l}93.8 \text { ( } 5 \text { years); } \\
92 \text { (10 years) }\end{array}$ & $\begin{array}{l}95.5 \text { ( } 5 \text { years); } \\
81 \text { (10 years) }\end{array}$ & 32 (10 years) \\
\hline Kalangos et al. (13) & 0 & 99.5 & $\begin{array}{l}94.5 \text { ( } 5 \text { years); } \\
92.7 \text { (10 years) }\end{array}$ & $\begin{array}{l}93.2 \text { ( } 5 \text { years); } \\
86.5 \text { (10 years) }\end{array}$ \\
\hline El Oumeiri et al. (14) & 0 & $\begin{array}{l}94 \text { ( } 5 \text { years); } \\
81 \text { (10 years) }\end{array}$ & 94 (10 years) & $\begin{array}{l}86.5 \text { (5 years); } \\
86 \text { (10 years) }\end{array}$ \\
\hline Pomerantzeff et al. (15) & 0.9 & 86.4 (20 years) & 30.4 (20 years) & $\begin{array}{l}99.7 \text { (thromboembolism-free), } \\
95.6 \text { (endocarditis-free) in } 20 \text { years }\end{array}$ \\
\hline
\end{tabular}

$\mathrm{MV}$, mitral valve. 


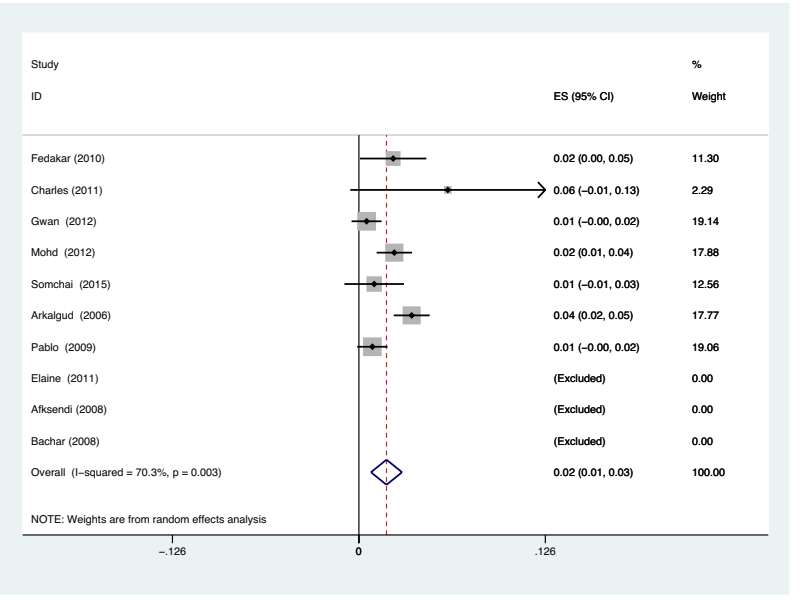

\begin{tabular}{|c|c|c|c|c|c|c|}
\hline Study & 1 & ES & [95\% Conf. & Incerval] & & Weight \\
\hline Fedakar (2010) & 1 & 0.023 & 0.001 & 0.046 & & 11.30 \\
\hline Charles (2011) & 1 & 0.060 & -0.006 & 0.126 & & 2.29 \\
\hline $\operatorname{Kim} \quad$ (2014) & 1 & 0.005 & -0.005 & 0.015 & & 19.14 \\
\hline Mond (2013) & 1 & 0.024 & 0.012 & 0.036 & & 17.88 \\
\hline Somchai (2015) & 1 & 0.010 & -0.010 & 0.030 & & 12.56 \\
\hline Arkalgud (2006) & 1 & 0.036 & 0.024 & 0.048 & & 17.77 \\
\hline Pablo (2009) & 1 & 0.009 & -0.001 & 0.019 & & 19.06 \\
\hline Elaine (2011) & 1 & (Excluded) & & & & \\
\hline Afksendiyo (2008) & 1 & (Excluded) & & & & \\
\hline Bachar (2009) & i & (Excluded) & & & & \\
\hline$D+L$ pooled ES & 1 & 0.019 & 0.008 & 0.029 & & 100.00 \\
\hline \multicolumn{7}{|c|}{ Heterogeneity chi-squared $=20.22$ (d.f. $=6) p=0.003$} \\
\hline Estimate of betw & $n-s$ & tudy varian & ince Tau-sq & ruared $=0$. & & \\
\hline
\end{tabular}

Figure 2 30-day mortality after rheumatic MV repair surgery. MV, mitral valve; CI, confidence interval; ES, effect size.

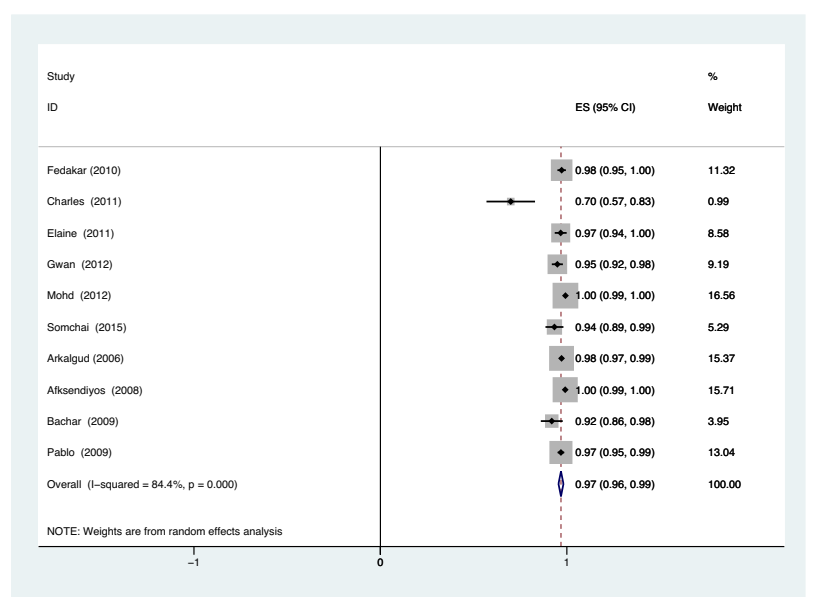

\begin{tabular}{|c|c|c|c|c|c|}
\hline Study & 1 & ES & [95: Conf. & Interval] & \& Weight \\
\hline Fedakar (2010) & 1 & 0.976 & 0.953 & 0.999 & 11.32 \\
\hline Charles (2011) & 1 & 0.702 & 0.571 & 0.833 & 0.99 \\
\hline Elaine (2011) & 1 & 0.971 & 0.939 & 1.003 & 8.58 \\
\hline $\operatorname{Kim}(2012)$ & 1 & 0.953 & 0.923 & 0.983 & 9.19 \\
\hline Mohd (2012) & 1 & 0.997 & 0.992 & 1.001 & 16.56 \\
\hline Somchai (2015) & I & 0.938 & 0.889 & 0.986 & 5.29 \\
\hline Arkalgud (2006) & 1 & 0.976 & 0.966 & 0.986 & 15.37 \\
\hline Afksendiyos (2008) & 1 & 0.995 & 0.987 & 1.004 & 15.71 \\
\hline Bachar (2009) & 1 & 0.923 & 0.864 & 0.982 & 3.95 \\
\hline Pablo (2009) & 1 & 0.972 & 0.955 & 0.990 & 13.04 \\
\hline$D+I$ pooled ES & I & 0.973 & 0.959 & 0.986 & 100.00 \\
\hline
\end{tabular}

Heterogeneity chi-squared $=57.54$ (d.f. $=9) \mathrm{p}=0.000$

I-squared (variation in ES attributable to heterogeneity) $=\mathbf{8 4 . 4 8}$

Estimate of between-study variance Tau-squared $=0.0003$

Test of ES=0: $z=141.91 p=0.000$

Figure 3 Long-term survival after rheumatic MV repair surgery. MV, mitral valve; CI, confidence interval; ES, effect size.

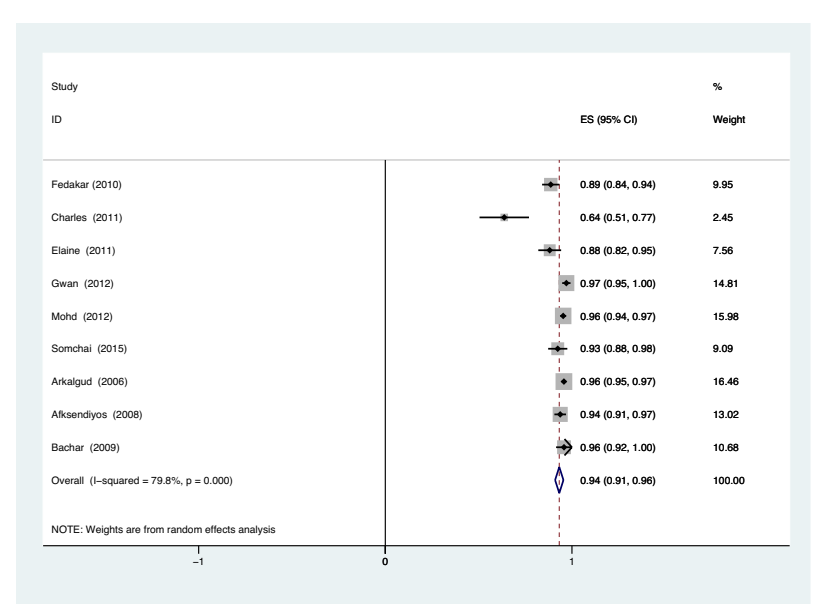

\begin{tabular}{|c|c|c|c|c|c|}
\hline Study & 1 & ES & [958 Conf. & Interval] & of Weight \\
\hline Fedakax (2010) & 1 & 0.890 & 0.844 & 0.937 & 9.95 \\
\hline Charles (2011) & 1 & 0.640 & 0.507 & 0.773 & 2.45 \\
\hline Elaine (2011) & 1 & 0.885 & 0.823 & 0.946 & 7.56 \\
\hline $\operatorname{Kim}(2012)$ & 1 & 0.974 & 0.952 & 0.997 & 14.81 \\
\hline Mond (2012) & 1 & 0.957 & 0.941 & 0.973 & 15.98 \\
\hline Somchai (2015) & 1 & 0.928 & 0.876 & 0.979 & 9.09 \\
\hline Arkalgud (2006) & 1 & 0.961 & 0.948 & 0.974 & 16.46 \\
\hline Afksendiyos (2008) & 1 & 0.941 & 0.910 & 0.972 & 13.02 \\
\hline Bachar (2009) & 1 & 0.962 & 0.919 & 1.004 & 10.68 \\
\hline D+L pooled ES & 1 & 0.936 & 0.914 & 0.959 & 100.00 \\
\hline
\end{tabular}

Heterogeneity chi-squared $=39.67$ (d.f. $=8$ ) $p=0.000$

I-squared (variation in ES attributable to heterogeneity) $=79.88$ Estimate of between-study variance Tau-squared $=0.0008$

Test of ES=0: $z=81.62 p=0.000$

Figure 4 Freedom from reoperation after rheumatic MV repair surgery. MV, mitral valve; CI, confidence interval; ES, effect size. 


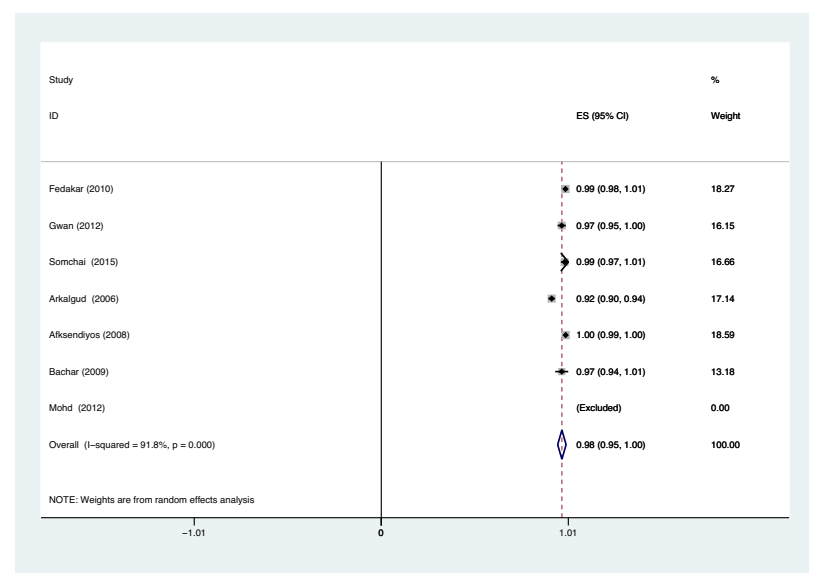

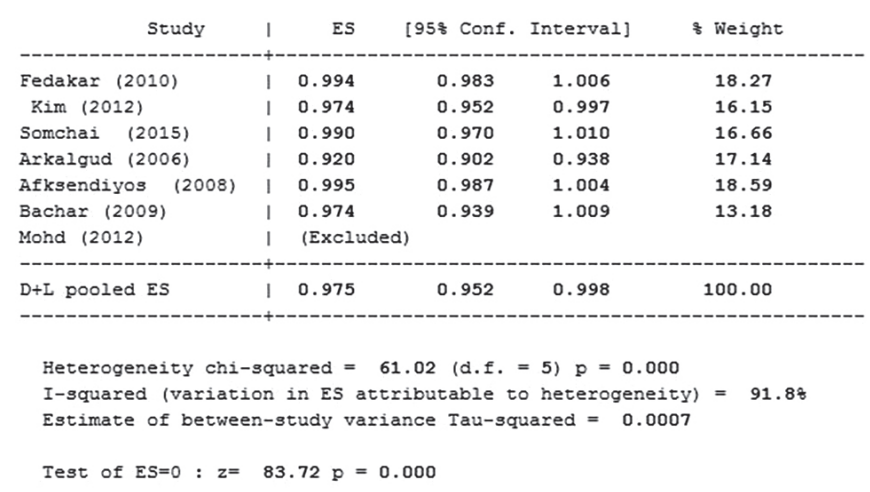

Figure 5 Freedom from adverse events after rheumatic MV repair surgery. MV, mitral valve; CI, confidence interval; ES, effect size.

adverse events in patients after rheumatic MV repair surgery was $97.5 \%$ (95\% CI, 95.2-99.8\%) (Figure 5).

\section{Discussion}

Rheumatic disease is the most common cause of MV disease in developing countries; it can adversely affect the MV and subvalvular apparatus, leading to calcification or fibrosis of the leaflet, commissure or chordal fusion, chordal or papillary muscle retraction, mitral annular calcification $(7,14)$. Rheumatic pathological features include $(16)$ : commissural fusion, shortening and fusion of chordae, leaflet thickening, especially at the free edges. Lesions of subvalvular apparatus and commissure are the main pathological features in Chinese patients with rheumatic MV disease (17). The diseased MV and subvalvular apparatus may alter hemodynamics, and result in valve failure and even cardiac death eventually. Both MV repair and replacement are effective surgical methods for $M V$ disease, which may be caused by degenerative MV disease, rheumatic MV disease and ischemic MV disease. The superiority of MV repair over replacement has been well established in patients with degenerative MV disease (18), in terms of lower hospital mortality (19), improved early and late survival rates, and fewer adverse postoperative complication (20). However, the optimal procedure for patients with rheumatic MV disease remains controversial. kuwaki and others suggested MV repair should be limited to a highly selected group of patients, only when excellent durability of repaired MV can be expected (21); meanwhile, rheumatic disease progression may reduce the durability of MV repair. Conversely, results of rheumatic MV repair in recent literature are promising (22). In this metaanalysis, pooled analysis showed 30-day mortality after MV repair surgery in patients with rheumatic MV disease is $1.9 \%$ (95\% CI, $0.8-2.9 \%$ ), and a long-term survival of 97.3\% (95\% CI, 95.9-98.6\%); freedom from reoperation was $93.6 \%$ (95\% CI, 91.4-95.9\%). Median sternotomy was the standard surgical approach for all patients. A previous meta-analysis (23) comparing MV repair with replacement in 3,227 patients with RHD proposed that MV repair should be attempted in patients with RHD. These authors extracted data from seven selected studies, performed a pooled analysis and showed that the MV repair group has lower 30-day mortality, higher long-term survival, fewer postoperative major adverse events than the MV replacement group, while displaying an acceptable reoperation rate. Another study (11) suggested MV repair is a better alternative to valve replacement for RHD patients, corroborating the findings in the current meta-analysis.

Pooled analysis showed that freedom from adverse events in patients after rheumatic MV repair surgery was $97.5 \%$ (95\% CI, 95.2-99.8\%). Adverse events in the studies assessed here were thromboembolism, hemorrhage, cerebral embolism, hemolysis, and infective endocarditis. Left ventricular function could be better preserved after MV repair, and short and long-term incidence of death caused by left ventricular dysfunction is decreased, and avoiding the use of long-term anticoagulants after the repair procedure can also reduce the incidence of anticoagulantand valve-related adverse events, including intracerebral hemorrhage, cerebral embolism, infective endocarditis, and valve failure $(24,25)$. Therefore, $M V$ repair should be the preferred surgical strategy for rheumatic MV when feasible. 
Even in children, valve replacement is not the most optimal method because of the small size of the implanted valve and rapid bioprosthesis degeneration, and use of anticoagulation therapy drugs after $M V$ replacement may adversely affect growth, marriage and pregnancy $(26,27)$. Similarly, MV repair is superior to replacement in children with RHD and should also be the procedure of choice in youths (28-30). However, in patients with rheumatic mitral-aortic valve disease, $M V$ repair may have less durability with abolished survival advantage; in this case, MV replacement may be the preferable surgical treatment for dual valve surgery (20).

Previous studies (31) reported that repaired MV has less durability and a higher rate of potential valve failure in rheumatic patients compared with patients with degenerative disease; however, a long-term follow-up study (4) showed that 10-, 20-, 30-year survival rates after MV repair in rheumatic patients are comparable with values obtained for degenerative patients ( $\mathrm{P}>0.05$, respectively). Meanwhile, 10- and 20-year freedom from reoperation rates were lower in rheumatic patients than those with degenerative disease $(\mathrm{P}<0.001$, respectively); 30-year freedom from reoperation in rheumatic patients was extremely low with only $10 \%$. Another study (32) did not state that repair for rheumatic MV disease is inferior to that of degenerative $\mathrm{MV}$ disease even in terms of reoperation rate. The authors found no statistically significant difference in early mortality, 5- and 10-year survival, 5- and 10-year freedom from reoperation, and 5- and 10-year valve failure between the two groups ( $\mathrm{P}>0.05$, respectively); in addition, durability of rheumatic MV repair was as outstanding as that of degenerative MV repair. The discrepant reoperation rates in the two studies might due to shorter follow-up years and the higher rate of ring implanted in rheumatic patients in the latest study (mean follow-up time, 47.8 months; ring implantation rate, $80.1 \%$ ) compared with the long-term follow-up study (follow-up of 30 postoperative years; ring implantation rate, $31.6 \%)$.

About $22.2 \%$ to $75.0 \%$ of patients with rheumatic MV disease underwent MV repair in existing literature (6,9,14,33-35). Dillon et al. (32) evaluated 253 patients with MV repair and 370 with MV replacement for RHD, and observed that the feasibility of $M V$ repair in patients with RHD aged 40 years or more is $40.6 \%$, and feasibility of MV repair in patients with RHD differed with patient age (48.7\% in patients aged $\leq 55$ years and $34.5 \%$ in those aged $>55$ years). The wide range of feasibility of MV repair in patients with RHD in different institutions may result from numerous predictors affecting postoperative outcomes. Risk factors associated with early and late outcomes of MV repair in patients with rheumatic MV disease have been reported in the studies included here and other relevant reports. Early reoperation and valve failure always result from technique failure and indication error (26). In the study from Yakub et al. (10), univariate and multivariate analyses identified long cardiopulmonary and aortic cross clamp time, older age, and emergency surgery as important predictors for early mortality, corroborating Bernal's finding (36). Related factors that affected late outcomes can be listed as follows. The first one is patient age. Advanced rheumatic inflammatory activity may increase the possibility of failure of initial repair in young patients (37). Yakub et al. (10) and Yankah et al. (7) reported that younger patients (below 20 years of age) have worse results in terms of reoperation rate and valve failure compared with older individuals. Yankah and colleagues reported actual survival in patients $<20$ years old is much higher than that of those above 20 years old. In another large study (34), reoperation rate was $23.6 \%$ in patients aged 20 years or younger compared with $9.6 \%$ in those above 20 years of age. The second factor is MV severity and type as well as subvalvular apparatus pathology (isolated MR, or mixed stenosis and regurgitation). Repairing mixed lesions is technically more challenging than managing pure MR lesions. Fedakar and colleagues (6) divided rheumatic patients into pure MR group and mixed MR/MS group according and found that MV pathology type does not affect postoperative morbidity or mortality; indeed, mixed lesion of MV could be repaired as efficiently as pure $\mathrm{MR}$, and the difference in reoperation rate between the two group was not statistically significant. Yankah et al. (7) proposed that both pure MR and mixed lesions can be reparable; however, durability of pure MR repair is much higher than that of mixed lesion repair. Other studies $(10,38)$ reported that presence of mixed $\mathrm{MR}$, stenosis, and repair at younger age are significant risk factors for a higher rate of late valve failure and reoperation. The third factor is the moment of surgery. Elaine et al. (8) believe that the earlier the surgery, the better the results of successful MV repair (e.g., preservation of left ventricular function). Indeed, if surgical treatment is very late, persistence or recurrence of rheumatic disease may adversely aggravate the lesions of $M V$ and subvalvular apparatus, compromising MV repair outcomes. The latter authors also reported that presence of moderate pulmonary hypertension preoperatively may increase by almost twice the risk of reoperation, so does worsening of mitral or functional class during the postoperative follow-up 
period. Geldenhuys and colleagues (1) suggested that leaflet procedures may be associated with reduced durability of rheumatic MV repair. As additional factors: presence of acute rheumatic carditis at the moment of surgery leads to a higher rate of late valve failure; postoperative mitral dysfunction increases reoperation rate; progression of rheumatic disease may significantly influence the outcome. Therefore, penicillin prophylactic treatment even after successful rheumatic MV repair surgery is crucial and an effective prevention strategy, and recent guidelines advise lifelong use (39). Optimal selection of patients with acute rheumatic activity at the time of operation and suitable MV morphology for repair may contribute to satisfactory rheumatic MV repair.

\section{Limitations}

As the major limitation of this systematic review, all the included studies were retrospective, which may reduce the value of this meta-analysis. In addition, surgeons used various reparative techniques in the included studies, partly depending on their experience. This factor might have affected long-term results. Furthermore, procedures bias, or detection bias, also influenced the results of this metaanalysis. Hence, further studies are needed to accurately evaluate rheumatic MV repair.

\section{Conclusions}

The outcome of rheumatic MV repair is outstanding in terms of low early mortality, high long-term survival, and freedom from valve-related complications, which may be very common in patients after rheumatic MV replacement. Meanwhile, reoperation rate after initial surgery is acceptable. Surgeons may try to repair MV in rheumatic heart disease when it is feasible. This suggests the need for further studies to identify indications which guide the selection of most optimal patients with rheumatic heart disease for MV repair.

\section{Acknowledgements}

Funding: The study was supported by the National Natural Science Foundation of China (No. 81270215).

\section{Footnote}

Conflicts of Interest: The authors have no conflicts of interest to declare.

\section{References}

1. Geldenhuys A, Koshy JJ, Human PA, et al. Rheumatic mitral repair versus replacement in a threshold country: the impact of commissural fusion. J Heart Valve Dis 2012;21:424-32.

2. Rheumatic fever and rheumatic heart disease. World Health Organ Tech Rep Ser 2004;923:1-122.

3. Kim JB, Kim HJ, Moon DH, et al. Long-term outcomes after surgery for rheumatic mitral valve disease: valve repair versus mechanical valve replacement. Eur J Cardiothorac Surg 2010;37:1039-46.

4. DiBardino DJ, ElBardissi AW, McClure RS, et al. Four decades of experience with mitral valve repair: analysis of differential indications, technical evolution, and longterm outcome. J Thorac Cardiovasc Surg 2010;139:76-83; discussion 83-4.

5. Stroup DF, Berlin JA, Morton SC, et al. Meta-analysis of observational studies in epidemiology: a proposal for reporting. Meta-analysis Of Observational Studies in Epidemiology (MOOSE) group. JAMA 2000;283:2008-12.

6. Fedakar A, Sasmazel A, Bugra O, et al. Results of mitral valve repair in rheumatic mitral lesions. Heart Surg Forum 2010;13:E86-90.

7. Yankah CA, Siniawski H, Detschades C, et al. Rheumatic mitral valve repair: 22-year clinical results. J Heart Valve Dis 2011;20:257-64.

8. Severino ES, Petrucci O, Vilarinho KA, et al. Late outcomes of mitral repair in rheumatic patients. Rev Bras Cir Cardiovasc 2011;26:559-64.

9. Kim GS, Lee CH, Kim JB, et al. Echocardiographic evaluation of mitral durability following valve repair in rheumatic mitral valve disease: impact of Maze procedure. J Thorac Cardiovasc Surg 2014;147:247-53.

10. Yakub MA, Dillon J, Krishna Moorthy PS, et al. Is rheumatic aetiology a predictor of poor outcome in the current era of mitral valve repair? Contemporary longterm results of mitral valve repair in rheumatic heart disease. Eur J Cardiothorac Surg 2013;44:673-81.

11. Waikittipong S. Mitral valve repair for rheumatic mitral regurgitation: Mid-term results. Asian Cardiovasc Thorac Ann 2015;23:658-64.

12. Kumar AS, Talwar S, Saxena A, et al. Results of mitral valve repair in rheumatic mitral regurgitation. Interact Cardiovasc Thorac Surg 2006;5:356-61.

13. Kalangos A, Christenson JT, Beghetti M, et al. Mitral valve repair for rheumatic valve disease in children: midterm results and impact of the use of a biodegradable mitral 
ring. Ann Thorac Surg 2008;86:161-8; discussion 168-9.

14. El Oumeiri B, Boodhwani M, Glineur D, et al. Extending the scope of mitral valve repair in rheumatic disease. Ann Thorac Surg 2009;87:1735-40.

15. Pomerantzeff PM, Brandão CM, Leite Filho OA, et al. Mitral valve repair in rheumatic patients with mitral insuficiency: twenty years of techniques and results. Rev Bras Cir Cardiovasc 2009;24:485-9.

16. Harb SC, Griffin BP. Mitral Valve Disease: a Comprehensive Review. Curr Cardiol Rep 2017;19:73.

17. Tiange L, Xu M. Repair Strategies Based on Pathological Characteristics of the Rheumatic Mitral Valve in Chinese Patients. Heart Lung Circ 2017. [Epub ahead of print].

18. Braunberger E, Deloche A, Berrebi A, et al. Very longterm results (more than 20 years) of valve repair with carpentier's techniques in nonrheumatic mitral valve insufficiency. Circulation 2001;104:I8-11.

19. Dayan V, Soca G, Cura L, et al. Similar survival after mitral valve replacement or repair for ischemic mitral regurgitation: a meta-analysis. Ann Thorac Surg 2014;97:758-65.

20. Saurav A, Alla VM, Kaushik M, et al. Outcomes of mitral valve repair compared with replacement in patients undergoing concomitant aortic valve surgery: a metaanalysis of observational studies. Eur J Cardiothorac Surg 2015;48:347-53.

21. Kuwaki K, Kawaharada N, Morishita K, et al. Mitral valve repair versus replacement in simultaneous mitral and aortic valve surgery for rheumatic disease. Ann Thorac Surg 2007;83:558-63.

22. Antunes MJ. Repair of rheumatic mitral valve regurgitation: how far can we go? Eur J Cardiothorac Surg 2013;44:689-91.

23. Wang Z, Zhou C, Gu H, et al. Mitral valve repair versus replacement in patients with rheumatic heart disease. $\mathrm{J}$ Heart Valve Dis 2013;22:333-9.

24. Wang YC, Tsai FC, Chu JJ, et al. Midterm outcomes of rheumatic mitral repair versus replacement. Int Heart J 2008;49:565-76.

25. Talwar S, Mathur A, Choudhary SK, et al. Aortic valve replacement with mitral valve repair compared with combined aortic and mitral valve replacement. Ann Thorac Surg 2007;84:1219-25.

26. Talwar S, Rajesh MR, Subramanian A, et al. Mitral valve repair in children with rheumatic heart disease. J Thorac Cardiovasc Surg 2005;129:875-9.

27. Reddy PK, Dharmapuram AK, Swain SK, et al. Valve repair in rheumatic heart disease in pediatric age group.
Asian Cardiovasc Thorac Ann 2008;16:129-33.

28. Remenyi B, Webb R, Gentles T, et al. Improved longterm survival for rheumatic mitral valve repair compared to replacement in the young. World J Pediatr Congenit Heart Surg 2013;4:155-64.

29. Enriquez-Sarano M, Schaff HV, Orszulak TA, et al. Valve repair improves the outcome of surgery for mitral regurgitation. A multivariate analysis. Circulation 1995;91:1022-8.

30. Kumar AS, Rao PN, Saxena A. Results of mitral valve reconstruction in children with rheumatic heart disease. Ann Thorac Surg 1995;60:1044-7.

31. Chauvaud S, Fuzellier JF, Berrebi A, et al. Long-term (29 years) results of reconstructive surgery in rheumatic mitral valve insufficiency. Circulation 2001;104:I12-5.

32. Dillon J, Yakub MA, Kong PK, et al. Comparative longterm results of mitral valve repair in adults with chronic rheumatic disease and degenerative disease: is repair for "burnt-out" rheumatic disease still inferior to repair for degenerative disease in the current era? J Thorac Cardiovasc Surg 2015;149:771-7; discussion 777-9.

33. American College of Cardiology; American Heart Association Task Force on Practice Guidelines (Writing Committee to revise the 1998 guidelines for the management of patients with valvular heart disease); Society of Cardiovascular Anesthesiologists, et al. ACC/ AHA 2006 guidelines for the management of patients with valvular heart disease: a report of the American College of Cardiology/American Heart Association Task Force on Practice Guidelines (writing Committee to Revise the 1998 guidelines for the management of patients with valvular heart disease) developed in collaboration with the Society of Cardiovascular Anesthesiologists endorsed by the Society for Cardiovascular Angiography and Interventions and the Society of Thoracic Surgeons. J Am Coll Cardiol 2006;48:e1-148.

34. Choudhary SK, Talwar S, Dubey B, et al. Mitral valve repair in a predominantly rheumatic population. Longterm results. Tex Heart Inst J 2001;28:8-15.

35. Bakir I, Onan B, Onan IS, et al. Is rheumatic mitral valve repair still a feasible alternative?: indications, technique, and results. Tex Heart Inst J 2013;40:163-9.

36. Bernal JM, Rabasa JM, Vilchez FG, et al. Mitral valve repair in rheumatic disease. The flexible solution. Circulation 1993;88:1746-53.

37. Kalangos A. The rheumatic mitral valve and repair techniques in children. Semin Thorac Cardiovasc Surg Pediatr Card Surg Annu 2012;15:80-7. 
38. Antunes MJ. Valve repair for rheumatic mitral regurgitation: still worthwhile? J Heart Valve Dis 2011;20:254-6.

39. Gerber MA, Baltimore RS, Eaton CB, et al. Prevention of rheumatic fever and diagnosis and treatment of acute Streptococcal pharyngitis: a scientific statement from the American Heart Association Rheumatic Fever,
Endocarditis, and Kawasaki Disease Committee of the Council on Cardiovascular Disease in the Young, the Interdisciplinary Council on Functional Genomics and Translational Biology, and the Interdisciplinary Council on Quality of Care and Outcomes Research: endorsed by the American Academy of Pediatrics. Circulation 2009;119:1541-51.

Cite this article as: Fu JT, Popal MS, Zhang HB, Han W, Hu QM, Meng X, Ma CY. A meta-analysis of late outcomes of mitral valve repair in patients with rheumatic heart disease. J Thorac Dis 2017;9(11):4366-4375. doi: 10.21037/ jtd.2017.10.97 